\title{
China, Thailand and Globalization
}

\author{
Arthayudh Srisamoot
}

Globalization literature underscores the flows of people, information, technologies, capital and ideas across national borders. ${ }^{1}$ Globalization contains both "good" and "bad" influences, but in general creates positive impacts and greater prosperity to all involved. Globalization increases the production of goods and services, creating a bigger "pie" for shared prosperity.

However, "change" remains one of the common denominators of globalization, a "constant" in a never-ending tide of transformation in the global environment.

An early version of globalization already took place when man emerged from their caves and started interacting with peoples from other caves. In the last few centuries, globalization has accelerated tremendously, at a scale unfathomable to "Moore's Law" or any supercomputer.

The year 2020-2021 however has seen a marked slowdown in the forces of globalization. The pace of change evident during the last few centuries of globalization has slowed down to a relative trickle over the past year. What felt like riding in a jet plane has now slowed down to the equivalent of riding in a prop plane.

In this short period, the world has witnessed not only economic slowdown, but also increasing uncertainty. This has a global phenomenon, touching all peoples, all countries, all continents and emerging as the new normal in our world. This increasing uncertainty has fed the fears and anxiety of the peoples of many countries, and this new normal of increasing uncertainty will remain with us for the foreseeable future.

Our challenge is how to navigate Asia in the midst of this volatility.

\footnotetext{
${ }^{1}$ Appadurai (1996).
}

A. Srisamoot (凶)

Embassy of the Kingdom of Thailand to the People's Republic of China, Beijing, China 


\section{The Rise of Asia}

The rise of Asia has happened before. Ancient China was the Middle Kingdom, abundant in resources and population and a rich civilization that was the envy of the world. After World War II, Japan rose to become an economic superpower and started the first wave of Asian economic growth in the modern era, helping to fuel industrial output and economic growth in many other countries in Asia, including Thailand. Fueled by stable government and strong economic policies, and partly due to the influx of Japanese investment in the automotive sector, electronics and infrastructure, Thailand was the world's fastest-growing economy in the decade 1985-1994 according to the World Bank. Real gross domestic product (GDP) per capita increased at an average rate of $8.2 \%$ each year during this period. ${ }^{2}$ Foreign direct investment poured into the country.

Not much earlier, in the late 1970s, China began to open up, and Thailand was one of the first foreign countries to expand into the Chinese market. The CP Group began investing in China under Chia Tai Co., Ltd. in Shenzhen as the first foreign investor in China, giving the company the registration number "0001". 3 According to the Ministry of Foreign Trade and Economic Cooperation (MOFTEC), there were approximately 3,129 Thai investment projects in China during the period from 1978 to 2002 with a contractual value of USD 5.6 billion. $^{4}$

The second wave of Asian economic growth began in the 1990s led by the Four Tigers-South Korea, Taiwan, Hong Kong and Singapore. By the early 2000s, these countries had developed into highly industrialized and high-income economies.

Following the opening up of China in 1979 and the combination of strong leadership, liberal policies and influx of foreign investment into the country over the last four decades, China has led a third wave of economic growth in Asia, which began in the late 2000s. With its "win-win" doctrine and inclusive policies, the "Belt and Road Initiative," the AIIB and other supportive measures, China now carries the mantle of a driver of growth in other countries.

\section{2 “Zhong-Tai Yi Jia Qin" (China and Thailand are One Family)}

Historically, it would not be incorrect to say that cross-border migration and exploration of economic opportunities between Thailand and China are one of the main factors that has created strong ties and firm connections between the Thai and Chinese peoples. The discovery of "Ban Chiang" pottery found in northeast Thailand, which dates from 1,800-5,000 years ago, may have originated from central China during

\footnotetext{
${ }^{2}$ Phongpaichit (1996).

${ }^{3}$ Milestones, CP Group.

${ }^{4}$ Manarungsan, Thailand-China Cooperation in Trade, Investment and Official Development Assistance.
} 
the Song period. ${ }^{5}$ There are also official records of trade missions between the Yuan Dynasty and the Sukhothai Kingdom from the thirteenth century. ${ }^{6}$

On the regional front, 2021 marks the 30th Anniversary of the ASEAN-China dialog process, which started in 1991, evolving into a strategic and comprehensive partnership covering all sectors of cooperation and fostering an intensive network of cooperation between the countries of Southeast Asia and China. This has ultimately resulted in ASEAN and China becoming each other's largest trading partner and travel destination.

As a founding member of ASEAN in 1967, Thailand is proud to have contributed to the development of this partnership. When I served as Director-General for ASEAN Affairs during Thailand's coordinatorship with China in the years 20122015, I can recall the highlights of this relationship such as the inaugural meeting at the ASEAN-China Centre in Beijing in 2012, the opening of the Permanent Mission of China to ASEAN in 2012, the celebrations for the 10th Anniversary of the ASEANChina Strategic Partnership in 2013 as well as the start of the Consultations for the Code of Conduct in the South China Sea that year, the emphasis on connectivity through the "One-Belt-One-Road" (later to be renamed "Belt and Road Initiative") in 2013, setting up of the Asian Infrastructure Investment Bank (AIIB) in 2015 to fund infrastructure and connectivity projects in Asia and beyond and the inauguration of the Lancang-Mekong Cooperation (LMC) in 2015 to foster closer cooperation among the 330 million people in riparian countries along the Mekong River.

\section{Regional Cooperation Economic Partnership or RCEP}

More recently, Thailand has made tremendous efforts during its chairmanship of ASEAN in 2019 to finalize the RCEP, often hosting monthly trade negotiation meetings to accelerate the conclusion of the RCEP, an idea initially conceived in 2011. Finally, on November 4, 2019, at the conclusion of the 35th ASEAN Summit in Bangkok, the leaders were witness to the conclusion of the substantive negotiations of the RCEP. The official RCEP Agreement was signed at a virtual summit hosted by Vietnam on November 15, 2020, and will come into force 60 days after it has been ratified by at least six ASEAN and three non-ASEAN signatories.

The 15-member RCEP countries account for about $30 \%$ of the world's population, or 2.2 billion people and $30 \%$ of global GDP as of 2020, the biggest trade bloc in history. Through the ASEAN Free Trade Area proposed by Thailand in 1992 and subsequently formed, ASEAN GDP increased from USD 600 billion in 2000 to USD 1.9 trillion in 2010 to USD 3.2 trillion in 2020.

\footnotetext{
5"Patterned Pottery from the Earliest Agricultural Communities of Thailand." Edited by The British Museum.

${ }^{6}$ Donnapee, Sineeporn, et al. "The Regulation of Chinese Medicine in Thailand," 2021.
} 
For the last ten plus years, the ASEAN market has been the largest trading partner for every ASEAN country, as well as China's largest trading partner. It is hard to imagine the potential of the larger single market will be for its membership.

Rather than a new conception, the RCEP is a culmination of preexisting bilateral FTAs between its members. Nevertheless, it is an upgraded version, containing new areas of agreement covering not only trade, investment and services, but new sectors such as standards and technology, technical cooperation, intellectual property and e-commerce, among others. RCEP signatories not only feature the largest population combined and the highest combined GDP, they also represent the most diversified membership structure, with different economic models used among signatory states. The agreement is intended to help unify supply chains and standards and reduce export costs and non-trade barriers.

The region is not only rich in natural resources, it is also a manufacturing powerhouse. The group accounts for $50 \%$ of global manufacturing output, $50 \%$ of global automobile production and as much as $70 \%$ of electronics production.

On investments, the RCEP accounts for $16 \%$ of global FDI stock, more than $24 \%$ of flows and has shown a consistent upward trend until last year. More importantly, under the RCEP, tariffs on around $92 \%$ of goods will be eliminated within 20 years, and non-tariff barriers will be reduced. This will allow member nations to gain preferential market access with each other, which will further maximize the potential of connectivity initiatives in the region, including China's Belt and Road Initiative, in strengthening regional supply chains in the post-pandemic recovery period.

It is fair to say that the RCEP will also be relevant to all sectors, not only for businesses, but also for consumers, farmers, bankers and particularly future generations. The RCEP comes at a time of major economic upheaval. The COVID-19 pandemic has led to a 30-40\% drop in FDI in 2020. With the RCEP in force, more investment will come from outside the region, even against the backdrop of global pandemic, which will help reduce the impact of COVID-19 on economies in the region. The RCEP can be a source economic recovery post-COVID, which will help to ensure the opening of markets as well as uninterrupted supply chains.

In fact, the RCEP seems like a combination of the first, second and third waves of Asian economic growth and is sure to have a progressive effect in this era of stagnant globalization.

\section{Not Limited to Trade}

The change in global economic order is not limited to trade. BREXIT has sent a strong message that globalization is reversible. The growth of the European Union from the humble European Coal and Steel Community was once glorified as a model of regional integration. But, after a decade of debt crisis, lax monetary policies, unstable politics and migration issues, the future outlook of a prosperous unified EU is hanging in the balance. 
In addition to the uncertainties in the world of trade and finance, we have also witnessed increasing impacts of modern technology. A decade ago, terms such as artificial intelligence (AI), Internet of Things (IoT) and Fintech would have been regarded more as novel ideas, rather than the reality that they have become. Today, these technologies are experiencing exponential growth. More importantly, they are replacing traditional employment with technically and digitally intensive jobs that require complete rebuilding of fundamental work skills. Professor Klaus Schwab, Founder and Executive Chairman of World Economic Forum, refers to these phenomena as the Fourth Industrial Revolution. The German government calls it "Industrie 4.0," we call it "Thailand 4.0," and the Japanese call it "Society 5.0". But no matter what you call it, we share the common apprehension that the replacement of "low-skill/low-pay" workers with "high-skill/high-pay" workers will inevitably increase social tensions. It is precisely this delicate situation that populism feeds upon. The success of nationalist and Rust Belt politics in the Western world clearly demonstrate how much anxiety and distrust in technology and globalism now exist among the general public.

Globalism is indeed at a crossroads between inclusiveness and inequality. The book "The Great Escape" by Professor Angus Deaton, ${ }^{7}$ winner of the 2015 Nobel Prize in economics, demonstrates how innovation and sustained growth that occurred a few centuries ago in today's developed nations led to global inequality. The noninclusive nature of this growth has caused the inequality gap between the rich and the poor to widen. Today, innovation and technology are again driving global inequality. But this time, we should learn from history. Asia must embrace research, development and innovation and ensure that the workforce adapts well to the changing global environment.

\section{Thailand's Policies}

Developing countries like Thailand, after having experienced many decades of rapid growth, are now experiencing stagnating or declining economic growth, and the main challenge is how to revitalize growth and overcome the middle-income trap. With declining birth rates and a rapidly aging workforce, the Thai Government has embarked on a renovation of the Thai economy by upgrading the entire infrastructure and transport network, including the provision of high-speed train lines and expanded sea ports, reforming our educational system and renewing our production system to modernize our country into Thailand 4.0. The heart of this mission is the Eastern Economic Corridor or EEC, in which the Thai Government will invest USD 40 billion over the next five years.

Asia needs to also focus on human capital development. To be able to grow in a fast moving and highly uncertain geopolitical context, Asia needs a workforce well

\footnotetext{
${ }^{7}$ Deaton (2015).
} 
adapted to this changing environment. At the time when the market is highly responsive to modern digital technology, our countries will increasingly require greater application of science, technology and innovation in production lines. In fact, one may argue that there will be a significant paradigm shift in how we work and operate. The regional workforce will require a fundamental shift in skill sets. As a result, skills development, vocational training, promotion of STEM education and digital literacy are urgently needed to improve and transform productivity and competitiveness to match the technology of the future. In particular, the focus will be to create an integrated value chain by creating human resource development centers to build an ecosystem for the development of highly skilled personnel among SMEs and start-ups, through the creation and use of innovation.

Under this backdrop, Thailand intends to play its part by working with Northeast Asian countries to develop a single chain of production within mainland Southeast Asia, consisting of Cambodia, Laos, Myanmar Vietnam and Thailand or CLMVT. History has shown that modern technology can help revitalize subregional production in the region. Strengthening CLMVT connectivity will greatly enhance ASEAN integration and merge mainland ASEAN into a single market and production base. The CLMVT markets have been growing at the rate of 7-8\% per year over the last decade. With closer internal connectivity and enhanced linkage to ASEAN and the Asia-Pacific markets, CLMVT will contribute to and complement the global supply chain and the future of globalization. During Thailand's chairmanship of a similar subregional framework, the Ayewarady-Chao Phraya-Mekong Economic Cooperation Strategy or ACMECS, in 2018, the first ACMECS Masterplan was adopted for the period of 2019-2023 with the objective of building stronger, more inclusive CLMVT subregional cooperation in the context of the rapidly changing globalization and regional geopolitics. The Masterplan seeks to stimulate the development of necessary infrastructure, physical and digital, to support the foundation of a modern mainland ASEAN economy. Developments of projects under the Masterplan will complement the ASEAN Master Plan on Connectivity 2025 and will transform mainland ASEAN into a de facto "land bridge" between the Indian and the Pacific Oceans, linking the two biggest economies, namely India and China. Through cooperation with external development partners, ACMECS aims to make the CLMVT region a building block for inclusive growth and globalization with a human face.

In the face of global uncertainty, Asia must strengthen cooperation to build regional resilience and assume increasing responsibility to be the principal engine for the revival of the Asian economy. A revived Asian economy would rekindle the global economy. Then, with the growing global economy, the polarization within each country and between countries between globalism and neo-nationalism would fade away. We in Asia, therefore, carry within us the hope of ushering in a new era of peace and prosperity for both Asia and the world. To make this hope a reality, China, as an industrial and technological powerhouse, is an indispensable catalyst. 


\section{Eastern Economic Corridor (EEC)}

Thailand has pushed forward new innovative industries in the Eastern Economic Corridor (EEC) in order to attract partners, including China, to invest in what we call five keys S-curve and five new S-curve sectors.

Thailand's Eastern Economic Corridor (EEC) is an area-based development initiative under the Thailand 4.0 economic model. With an area-based development initiative, leveraging what has been Thailand's main industrial hub since 1980s, investors will experience a rewarding investment journey. The EEC is an important industrial base where the existing infrastructure of the Eastern Seaboard will be upgraded and expanded to attract a new wave of investments in high-tech industries, innovation and logistics.

Thailand's strategic geographical advantage will be further strengthened by EEC development. A large-scale investment to upgrade infrastructure in the area is underway. A high-speed rail link between Bangkok and the EEC area is being built and will be completed by 2025. It is one of the important linkage points through China's Belt and Road Initiative and will connect the Greater Bay Area (GBA) with ASEAN countries. As a prime gateway, the EEC will serve not only as a center for connection within ASEAN, but also as South East Asia's gateway to South Asia, the Middle East and Europe, through the integration of China's Belt and Road Initiative. A major focus of the EEC is to improve existing connectivity and foster manufacturing and innovation. The Royal Thai Government envisions that the EEC will become a regional logistics and transport hub providing a competitive edge in trade and supply chain management for a number of industries.

The EEC is an investment destination for Chinese investors. According to Thailand's Board of Investment (BOI) data, Chinese companies invested more than USD 1 billion in EEC area in 2019, an increase of 87\% compared to 2018. The BOI also predicted that China will remain at the top of Thailand's five biggest foreign investment values over the coming years. This potentially reflects a crucial role of the EEC as a part of the regional supply chain for Chinese investors.

\section{Bio-Circular-and-Green (BCG) Economic Model}

While trends in investment are promising for the success of the Eastern Seaboard project, Thailand does not overlook the social and environmental impact on local communities. To "build back better" post-COVID-19, Thailand seeks to ensure the region's long-term inclusive and sustainable growth by promoting a green and innovation-based economy, building on our rich biodiversity and natural resources. Thailand has adopted the "Bio-Circular-and-Green Economy Model" or "BCG Model" as our post-COVID-19 recovery strategy. The BCG Economic Model uses science, technology and innovation (STI) to increase the capacity and competitiveness of players throughout the value chain, both upstream and downstream, and 
support the transformation toward an environment-oriented economy by striking a balance between conserving natural resources and value creation. BCG is an integration of bioeconomics, circular economics and green economics, which seeks to capitalize on Thailand's biodiversity throughout the supply chain, by strengthening the capacity of local communities and optimizing the use of new technologies. At the same time, higher up the supply chain, science agencies are transforming the manufacturing and service sectors through modern scientific methods and technology, as well as homegrown innovation. The vision is to simultaneously drive forward the bio-, circular- and green economy. In short, Thailand plans to be innovative and go greener for better gains.

BCG builds on the principles of His Majesty King Bhumibol Adulyadej The Great's Sufficiency Economy Philosophy (SEP), whose notion of moderation is particularly relevant. Economic development should begin with producing from existing resources and strengthening local foundations toward creating balanced, stable growth and a self-sufficient economy. The BCG model will enable Sustainable Development Goals (SCGs) through the promotion of sustainable agriculture, clean energy and responsible consumption and production, ensuring the conservation and sustainable utilization of biodiversity and protecting environments and ecosystems. Thailand's four strategic areas for the BCG model are based on her economic foundations and strengths, namely (1) food and agriculture; (2) medical and wellness; (3) energy, material and biochemicals and (4) tourism and creative economy. Focusing on these, Thailand hopes to achieve comprehensive security in key areas of food, health, energy, employment and sustainable natural resources and environment.

By promoting balanced development that does not exceed environmental capacity, the EEC supports industries that correspond with the BCG, such as food for the future, medicine and agriculture and biotechnology. The BCG investments in the EEC will enjoy revised regulations in their favor. For instance, with regard to the circular economy, regulations have been revised so that industrial waste can be transported directly to processing plants across provinces, thereby minimizing the environmental risk to localities. A concrete example is the Thai Eastern Industrial Zone in Chonburi, set up in October 2020, the first bio-industrial zone that can generate an annual economic value of over USD 3.2 billion. Part of the EEC has been helping farmers develop quality products to feed the bio-industry and creating stable incomes and jobs for 8,000 locals over three years.

\section{Thai Cuisine: A Process of Transnational Interaction}

Thai cuisine has been a product of transnational interactions for centuries. What is known as Thai food today is in fact a combination of indigenous foods and the influences of Indian and Chinese culinary traditions. Thai food consists of variety of ingredients and herbs that come from a combination of Eastern and Western traditions. In fact, China has had substantive influence on Thai food. Its impact can 
be seen in several aspects, from cooking methods to raw ingredients. ${ }^{8}$ As of 2003 , there were 6,875 Thai restaurants overseas; $49 \%$ of them were in the USA and Canada; $20 \%$ were in Europe, $15 \%$ in Australia and New Zealand, 14\% in Asia and $2 \%$ in other countries. ${ }^{9}$

It is not simply because of its geographical position as a tropical country that Thailand produces so many different kinds of high-quality fruits. Thai food and fruit have become globally popular as a result of its unique characteristics and its rich flavors, derived from a huge variety of ingredients. According to a survey on cuisine perception conducted by the Kellogg School of Management and the Sasin Institute, Thai food was ranked number four-after Italian, French and Chinesewhen respondents were asked to name the first "ethnic cuisines" that came to mind. It was ranked number six behind Italian, French, Japanese, Chinese and Indian when people were asked "What is your favorite cuisine?"10. In promoting Thai cuisine internationally, the Royal Thai Government prioritizes standardization and quality. For more than ten years, the Royal Thai Government has implemented a project called "Kitchen of the World," which further enhanced the globalization of Thai cuisine. The internationalization of Thai cuisine demonstrates cultural and economic globalization that bring Thailand closer to people worldwide, including Chinese people.

\section{Culture and Tourism}

Globalization and tourism are interconnected. Globalization exists not only in the supply side of tourism, but it also defines the increasingly interconnected demand for tourism around the world. ${ }^{11}$ In other words, it has become nearly impossible to talk about connectivity between Thai and Chinese people without recognizing the contribution of tourism. In recent decades, people-to-people ties between Thailand and China have been greatly strengthened. Before COVID-19, there were more than 2,700 flights traveling weekly between Thailand and China-approximately 2 million seats every month. Chinese tourists have been at the top of Thailand's list of most frequent visitors for several years." ${ }^{12}$ In 2019, 10.99 million Chinese traveled to Thailand, a nearly fourfold increase from 2012. Meanwhile, approximately 870,000 Thai tourists traveled to China, which was a $4.6 \%$ increase from $2018 .{ }^{13}$ Thailand is also a top destination for medical and health services. In fact, the medical tourism industry is among Thailand's fastest-growing industries. According to the Global Wellness Institute's figures in 2017, Thailand ranked fourth in the list of the top ten wellness tourism markets in the Asia-Pacific and thirteenth on the list of the top

\footnotetext{
8"Why Thai Food Has Become So Popular Worldwide" (2018).

${ }^{9}$ Sunanta (2005).

${ }^{10}$ Ibid.

${ }^{11}$ Song et al. (2017).

${ }^{12}$ Published by Toutiao (2018).

${ }^{13}$ Lookwe (2019).
} 
twenty wellness tourism markets worldwide. ${ }^{14}$ As of 2019, Thailand had 66 hospitals and clinics that were accredited by the Joint Commission International with the JCI world-class standard, the highest number in Asia and ranking fourth in the world.

Cultural communication is also one of the key aspects underlying cross-cultural exchanges that strengthen bonds between the Thai and Chinese peoples. It is estimated that approximately $11-14 \%$ of the Thai population are ethnically Chinese. With such close interaction between the peoples and their geographical proximity, especially through the ASEAN Master Plan on Connectivity and the Belt and Road Initiative, it is hoped that this partnership will continue to strive for new heights. In 2021, China continues to be Thailand's largest trade partner and its largest investor nation. Thailand is China's third biggest trading partner in ASEAN and thirteenth in the world. Certainly, there is still more room for Thai and Chinese investors to cooperate and enjoy mutual benefit for our shared prosperity.

China and Thailand have maintained friendly relations for hundreds of years. With the growing development of the Internet, Thai dramas have also gained popularity in China in recent years. Research from 2015 showed that more than $51 \%$ of the Chinese tourists in Thailand had watched Thai TV dramas. ${ }^{15}$ The rapid development of online video platforms has made it easier for Chinese audiences to access more diverse Thai dramas. Likewise, Chinese dramas and TV series are also becoming more popular among young audiences in Thailand. These digital platforms have been a vehicle to promote Thai and Chinese culture and arts, naturally enhancing the integration and exchanges of cultures.

Today, China and Thailand are comprehensive strategic partners. Looking ahead, there is room for our relations to grow and deepen in many areas particularly in trade and investment, science, technology and innovation, industrial linkages, poverty eradication, public health, education as well as connectivity through regional linkage and the Belt and Road Initiative. While we strive to implement our respective national development strategies, cooperation, respect and mutual understanding remain the foundation upon which our peoples will grow together.

\section{References}

Appadurai A (1996) Modernity at large: cultural dimensions of globalization. University of Minnesota Press

Deaton A (2015) The Great Escape-health, wealth, and the origins of: inequality. Princeton University Press

Global Wellness Tourism Economy (2018) Global Wellness Institute, Nov. 2018, globalwellnessinstitute.org/wpcontent/uploads/2018/11/GWI_GlobalWellnessTourismEconomyReport.pdf.

Lookwe (2019) Thailand and China special edition dedicated to the 45th anniversary of the establishment of diplomatic relation between Thailand and China

Manarungsan S, Thailand-China cooperation in trade, investment and official development assistance. www.ide.go.jp/library/English/Publish/Download/Brc/pdf/01_thailandandchina.pdf

\footnotetext{
${ }^{14}$ Global Wellness Tourism Economy (2018).

${ }^{15}$ Shi (2020).
} 
Milestones, CP Group, www.cpgroupglobal.com/about/Milestones

"Over the Past Five Years, the Number of Weekly Flights between China and Thailand Rosed from 500 to 2700." Toutiao, Cover News, 30 July 2018. https://www.toutiao.com/i65837 90804425245191/?tt_from=weixin\&utm_campaign=client_share\&wxshare_count=1\&timest $\mathrm{amp}=1622277464 \& \mathrm{app}=$ news_article $\& u t m \_s o u r c e=$ weixin $\& u t m \_$medium $=$toutiao_android $\&$ use_new_style=1\&req_id=202105291637440102120440522B409769\&share_token=cde9aea7daa3-4486-9872-cfbb12d8bd2f\&group_id=6583790804425245191

Phongpaichit P (1996) “THE THAI ECONOMY IN THE MID-1990s." Southeast Asian Affairs. JSTOR, pp. 369-381. www.jstor.org/stable/27912162. Accessed 31 May 2021

Shi Y (2020) An analysis of the popularity of Thai television drama in China, 2014-2019. In: Proceedings of the $20203 \mathrm{rd}$ international conference on humanities education and social sciences (ICHESS 2020), vol 496. https://doi.org/10.2991/assehr.k.201214.587

Song H, Li G, Cao Z (2017) Tourism and economic globalization: an emerging research agenda. J Travel Res 0047287517734943

Sunanta (2005) The globalization of Thai cuisine. 14 Oct. 2005, citeseerx.ist.psu.edu/viewdoc/download?doi=10.1.1.404.1934\&amp;rep=rep1\&amp;type=pdf

"Why Thai Food Has Become So Popular Worldwide-Best Restaurant in Bangkok-Sukhumvit: Indulge Fusion Food \&amp; Cocktail Bar.” Edited by Indulge Fusion Food, Best Restaurant in Bangkok-Sukhumvit I Indulge Fusion Food \&amp; Cocktail Bar, 16 Nov. 2018, www.indulg ebangkok.com/2018/08/13/why-thai-food-has-become-so-popular-worldwide/

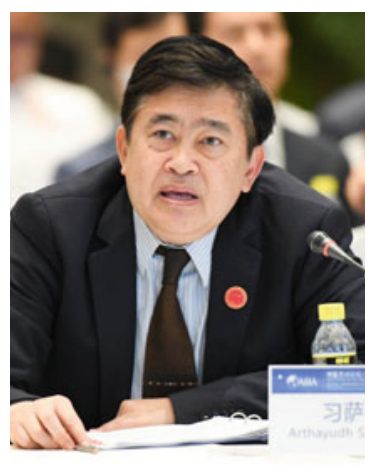

H.E. Mr. Arthayudh Srisamoot is the ambassador of the Kingdom of Thailand to the People's Republic of China. He has been the ambassador of Thailand to China since 2019. In 1988, he started his career in the Ministry of Foreign Affairs in the Department of ASEAN Affairs. He was Ambassador Extraordinary and Plenipotentiary to the Federal Republic of Austria, Slovak Republic and Republic of Slovenia and Permanent Representative to the United Nations and International Agencies in Vienna. Originally from Bangkok, he also spent time in the United States where he received his Bachelor of Sciences (Economics) from Monmouth College, and Master of Arts from the University of Chicago, Illinois.

Open Access This chapter is licensed under the terms of the Creative Commons AttributionNonCommercial-NoDerivatives 4.0 International License (http://creativecommons.org/licenses/bync-nd/4.0/), which permits any noncommercial use, sharing, distribution and reproduction in any medium or format, as long as you give appropriate credit to the original author(s) and the source, provide a link to the Creative Commons license and indicate if you modified the licensed material. You do not have permission under this license to share adapted material derived from this chapter or parts of it.

The images or other third party material in this chapter are included in the chapter's Creative Commons license, unless indicated otherwise in a credit line to the material. If material is not included in the chapter's Creative Commons license and your intended use is not permitted by statutory regulation or exceeds the permitted use, you will need to obtain permission directly from the copyright holder.

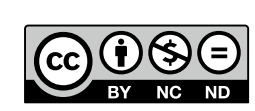

